\title{
Fractionation of Pinus radiata by ethanol-based organosolv process
}

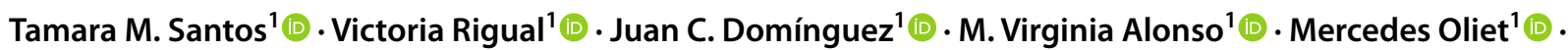 \\ Francisco Rodriguez ${ }^{1}$ (I)
}

Received: 7 October 2021 / Revised: 21 December 2021 / Accepted: 10 January 2022

(c) The Author(s) 2022

\begin{abstract}
The lignocellulosic materials are promising feedstock to produce biofuels and bioproducts in the biorefinery framework. However, a pretreatment step is required to disrupt lignin-carbohydrate complex. In this work, the fractionation of Pinus radiata wood into its main components, cellulose-rich delignified solid, recovered lignin after precipitation, and solublein-black liquor hemicellulose, was studied. For this purpose, an organosolv process employing ethanol/water mixture as solvent in absence of a catalyst was carried out. The effects of operating conditions on delignified solid were evaluated by using a $2^{3}$ central composite experimental design, being the responses delignified solid yield, delignification degree, hemicellulose content, and glucan content. The variables studied were temperature $\left(170-200{ }^{\circ} \mathrm{C}\right)$, time (50-100 min), and ethanol concentration (40-60\%). The increase of organosolv severity (temperature and time) and reduction of ethanol concentration favor the glucan enrichment of delignified solid, due to lignin removal and hemicellulose solubilization. A glucan content of more than $66 \%$ is obtained by applying temperature higher than $195{ }^{\circ} \mathrm{C}$ and time longer than $90 \mathrm{~min}$, when $40 \mathrm{wt} \%$ alcohol concentration is used. The liquid fraction obtained during the organosolv process (black liquors) was used to recover lignin and hemicellulosic fractions solubilized. Furthermore, hemicellulose and lignin content of delignified solid was correlated with the thermal stability measured as $\mathrm{T}_{10 \%}$.
\end{abstract}

Keywords Organosolv process $\cdot$ Softwood $\cdot$ Fractionation $\cdot$ Central composite design $\cdot$ TGA

\section{Introduction}

The lignocellulosic materials are considered as a promising feedstock to be utilized in the sustainable production of liquid fuels and chemical products in the biorefinery framework [1-3]. The main advantages of these materials are that they do not compete with food, low cost, and availability. They are mainly composed of cellulose, hemicellulose, lignin, and extractives. These components form the lignocellulosic matrix, being strongly bonded through covalent or non-covalent bonds [2]. To overcome the strong recalcitrant structure of these lignocellulosic biomasses, the pretreatment is crucial step to get the partial destruction of complex formed by lignin-carbohydrates [4]. Many methods have been proposed as pretreatment of lignocellulosic materials, being classified

Tamara M. Santos

tmsantos@ucm.es

1 Department of Chemical Engineering and Materials, Complutense University of Madrid, Avda Complutense s/n, 28040 Madrid, Spain into physical, physicochemical, chemical, and biological [2, $5,6]$. Among the chemical pretreatments, organosolv is considered as one of the most promising method [5, 7-9].

Organosolv process was originally developed as an alternative to the Kraft process within the context of the pulp and paper industry [10]. This process can be performed using different organic solvents, such as alcohols, organics acids, or other solvents, with or without catalyst $[7,11]$. The sulfuric acid, hydrochloric acid, and phosphoric acid can be used as catalysts $[1,3,4,12,13]$. Some of these solvents are ethanol [3, 13-18], methanol [19], butanol [20, 21], ethylene glycol [22], glycerol [1, 23, 24], acetic acid [12, 25], formic acid [26, 27], acetone [4, 28, 29], or $\gamma$-Valerolactone [30]. Among them, ethanol is considered a successful solvent for pretreatment at low boiling point. This alcohol presents some advantages, such as low cost, ease of recovery, and lack of toxicity [31-33].

After organosolv process, three main components from lignocellulosic biomass can be efficiently fractioned: high purity cellulose, hemicellulose-derived compounds, and high quality lignin, low in sulfur $[9,31]$. The cellulose 
remains in the solid fraction after pretreatment, while most lignin and hemicellulose are solubilized into solvent [34]. The organosolv lignin is recovered from black liquor by precipitation, and hemicellulose-derived compounds left in the liquid phase $[8,35,36]$. After the separation of components achieved in organosolv process, these fractions can be used to produce value-added chemicals.

The cellulose-rich fraction can be employed as substrate in enzymatic hydrolysis to be depolymerized to glucose [11, $14,18,29]$, or in simultaneous saccharification and fermentation step to produce biofuels $[6,17,37]$. After enzymatic hydrolysis step, the biohydrogen or acetone-butanol-ethanol (ABE) production has been studied [38, 39]. The biomethane production by anaerobic digestion has been also considered $[13,40]$. An integrated process composed of organosolv and fast pyrolysis, in which this cellulose-rich fraction is used to produce a platform chemical, levoglucosan, has been also proposed [41]. In addition, the organosolv pretreated solid rich in cellulose has been also employed for nanocellulose crystal (NCC) production, after bleaching step [42]. This cellulose-rich solid has been used for omega-3 fatty acids and lactic acid production, employing hydrolysis and microbial fermentation steps. For this purpose, an acid-free delignification process called Oxiorganosolv which employs oxygen gas was used to remove lignin and obtain the cellulosic fraction [43].

This delignified solid rich in cellulose has been characterized to determine its thermal stability, and confirm the removal of other components, such as lignin and hemicellulose, occurred during organosolv process [23, 41, 44, 45]. From the other side, through the Fourier transform infrared spectroscopy, the effect of organosolv process on this delignified solid is studied, and the modification of its chemical composition is confirmed [15, 23, 32, 37, 39, 41, 45]

The lignin obtained from organosolv process can be employed for multiple applications, such as precursor for carbon fiber [46], antioxidant [47], or substitute of the phenol in a phenolic adhesive formulations for plywood [48]. The organosolv lignin has been also used for hydrogel synthesis, showing suitable antifungal properties [49]. The hemicellulose-derived compounds, which remain in the liquid stream, have potential in the production of valuable products, such as isobutanol [50], ethanol [21], or furfural and hydroxymethylfurfural $[20,51]$. However, further steps are required, such as acid hydrolysis or the use of nanofiltration membrane and fermentation with transgenic $S$. cerevisiae [21, 51]. In addition, its use as a carbon source for the ligninolytic enzyme production or even its possible utilization as prebiotics has been also proposed [43, 52]. Thus, the organosolv pretreatment can be considered as a fractionation process of lignocellulosic feedstock. It not only gets the increment of enzymatic digestibility of cellulose by the removal the lignin and hemicellulose which act as barriers, but it also gets the obtainment of co-products from lignin and non-cellulosic polymer, fulfilling the requirements for the biorefinery concept $[8,26]$.

Several lignocellulosic materials have been employed as feedstocks for organosolv process, such as agricultural residues, crops, and woody biomass: poplar [18, 53], empty palm fruit bunch [54], Liriodendron tulipifera wood [14], Eucalyptus globulus wood [24], wheat straw [25], rice straw [1], date palm [34], almond and walnut shell [49], corn stover [22], sugarcane bagasse [19], barley straw [4], potato peel wastes [13], vine shoot [20], Cynara cardunculus [3], Eucalyptus pellita wood [51], Eucalyptus nitens bark [17], mustard biomass [29], rubber wood [40], beech wood [12], or Pinus taeda [33]. Among these materials, the woody biomasses are more resistant to organosolv compared to herbaceous, and softwoods present more recalcitrance than hardwood [41]. Softwoods exhibit more difficulty to be delignified than hardwoods due to higher lignin content, and higher content of guaiacyl units in lignin (G) [8].

The aim of the present work is to study the fractionation in its main components of a softwood, Pinus radiata, by an autocatalyzed organosolv process. The influence of operating conditions (ethanol concentration, temperature, and time) on delignified solid is evaluated by applying a $2^{3}$ central composite experimental design. The delignified solids are characterized by chemical composition, thermal stability, and chemical structure, and hemicellulose-derived compounds in black liquors are quantified by HPLC. The relationship between thermal stability, measured as $\mathrm{T}_{10 \%}$, and chemical composition of delignified solid is established. The results allow to determine the effectiveness of autocatalyzed organosolv process to get the fractionation of $P$. radiata wood in its components, which can be valorized in following steps within biorefinery concept.

\section{Materials and methods}

\subsection{Raw material and reagents}

The raw material, $P$. radiata wood, was provided by CIFORINIA ("Instituto Nacional de Investigación y Tecnología Agraria y Alimentaria"). Wood chips were milled and sieved to obtain a particle size between 0.30 and $2 \mathrm{~mm}$. Ethanol was supplied by Alcoholes Aroca with a purity of $96 \%$ $(\mathrm{v} / \mathrm{v})$. Chemicals used as standard reagents are D-(+)-glucose $(\geq 99.5 \%)$, D- $(+)$-xylose $(\geq 99 \%)$, D- $(+)$-mannose $(\geq 99.5 \%)$, D-(-)-arabinose $(\geq 98 \%)$, D- $(+)$-galactose $(\geq 99.5 \%)$, acetic acid $(\geq 99.7 \%)$, formic acid $(\geq 95 \%)$, furfural ( $\geq 99 \%)$, and 5-hydroxymethylfurfural $(\geq 99 \%)$ and were purchased from Sigma-Aldrich. Sulfuric acid (72\% w/w) from Fluka and calcium carbonate from Panreac were also employed. 


\subsection{Organosolv process}

Organosolv process was carried out in a 450-mL Parr reactor with a 4848 reactor controller (Parr Instrument Company) equipped with cooling bath (MPC-K6, Huber) that pumped and recirculated silicone oil as the cooling fluid. The feedstock, $20 \mathrm{~g}$ of pine wood (dry weight), was treated with an ethanol/water mixture using a solid/liquid ratio of $1 / 8(\mathrm{w} / \mathrm{v})$. The reaction mixture was heated for 50 min to desired temperature, and kept during the reaction time. After this time, the reactor was cooled down to $40{ }^{\circ} \mathrm{C}$, and the solid fraction (delignified solid) and liquid phase (black liquor) were separated by vacuum filtration in a Buchner and Kitasato system with a paper filter (1252 Filter-Lab). The delignified solid was washed with $160 \mathrm{~mL}$ of $\mathrm{NaOH}$ solution $0.4 \%(\mathrm{w} / \mathrm{w})$ and water in order to remove the maximum amount of lignin and other impurities present in the surface. Finally, the solid fraction was dried in an oven $\left(40{ }^{\circ} \mathrm{C}\right)$ before characterization. The delignified solid yield $\left(\mathrm{Y}_{\text {solid }}\right)$ was determined according to the Eq. (1):

$\Upsilon_{\text {solid }}(\%)=\frac{\text { Delignified solid }(\mathrm{g})}{\text { Raw material }(\mathrm{g})} \cdot 100$

where delignified solid is the amount of solid obtained after organosolv process, and raw material is the initial mass of $P$. radiata introduced to the reactor, both expressed in oven-dry basis.
The effects of experimental conditions ethanol concentration $(\mathrm{C})$, temperature $(\mathrm{T})$, and time $(\mathrm{t})$ of organosolv process on delignified solid were studied by using a $2^{3}$ central composite experimental design. The ranges of these independent variables were $40-60 \% \mathrm{w} / \mathrm{w}, 170-200{ }^{\circ} \mathrm{C}$, and $50-100 \mathrm{~min}$. The total number of runs was 17 , whose experimental conditions and severity factor $\left(S_{0}\right)$ are summarized in Table 1 . The software used to perform the multiple regression and analysis of variance (ANOVA) was Statgraphics Centurion XVII.

\subsection{Analysis of raw material and delignified solids}

The cellulose, hemicellulose, and lignin contents in the raw material and delignified solids were determined according to the NREL/TP-510-42,618 procedure [55]. The solid residue was determined gravimetrically and known as insoluble lignin (Klason lignin, IL). The soluble lignin (SL) was analyzed by a UV-Vis spectrophotometer (Cary 50, Varian) at $240 \mathrm{~nm}$. The monomeric sugars were quantified by HPLC (Agilent, 1260) equipped with a Refractive Index Detector. For this purpose, a Carbo SepCHO 682 column (Transgenomic) with Micro-Guard cartridges (Bio-rad) was employed using the following conditions: ultrapure water as mobile-phase with a flow rate of $0.4 \mathrm{~mL} / \mathrm{min}$, and a column temperature of $80{ }^{\circ} \mathrm{C}$. The sugar determination was performed after the samples were neutralized with calcium carbonate and filtered through membranes with a $0.22-\mu \mathrm{m}$ pore size. In the present work, the cellulose is referred as glucan content (Gl), while the sum of xylan, galactan, and mannan
Table 1 Experimental conditions and results obtained for delignified solid yield ( $\mathrm{g} / 100 \mathrm{~g}$ raw material), chemical composition of delignified solids ( $\mathrm{g} / 100 \mathrm{~g}$ delignified solid), and delignification degree (\%) of assays according to a $2^{3}$ central composite design

\begin{tabular}{llllllllllllll}
\hline Run & $\mathrm{C}_{\mathrm{EtOH}}(\mathrm{wt} \%)$ & $\mathrm{T}\left({ }^{\circ} \mathrm{C}\right)$ & $t(\mathrm{~min})$ & $\mathrm{S}_{0}$ & $\mathrm{Y}_{\text {solid }}$ & $\mathrm{Gl}$ & $\mathrm{X}$ & $\mathrm{Ga}$ & $\mathrm{M}$ & $\mathrm{HMC}$ & $\mathrm{SL}$ & $\mathrm{IL}$ & $\mathrm{DD}$ \\
\hline 1 & 33 & 185 & 75 & 4.38 & 59.0 & 58.6 & 3.9 & 0.4 & 6.1 & 10.4 & 3.9 & 24.4 & 45.9 \\
2 & 60 & 200 & 50 & 4.64 & 66.0 & 56.6 & 4.5 & 0.7 & 12.4 & 17.6 & 3.2 & 19.0 & 52.8 \\
3 & 50 & 210 & 75 & 5.11 & 43.5 & 71.0 & 4.1 & 0.4 & 7.2 & 11.7 & 4.3 & 11.1 & 81.8 \\
4 & 60 & 170 & 50 & 3,76 & 79.6 & 48.9 & 4.7 & 2.2 & 13.3 & 20.2 & 3.6 & 22.5 & 32.6 \\
5 & 60 & 170 & 100 & 4.06 & 77.4 & 47.7 & 4.5 & 2.0 & 13.5 & 20.0 & 4.9 & 21.2 & 38.2 \\
6 & 50 & 185 & 75 & 4.38 & 63.7 & 55.2 & 4.2 & 0.9 & 12.5 & 17.6 & 4.4 & 20.1 & 51.8 \\
7 & 50 & 185 & 75 & 4.38 & 65.9 & 56.2 & 4.1 & 0.7 & 11.7 & 16.5 & 4.6 & 17.7 & 56.1 \\
8 & 50 & 185 & 33 & 4.02 & 71.5 & 50.2 & 4.4 & 1.4 & 12.4 & 18.2 & 4.6 & 20.3 & 45.4 \\
9 & 50 & 185 & 75 & 4.38 & 65.7 & 54.3 & 4.2 & 0.9 & 12.0 & 17.1 & 4.3 & 18.9 & 53.3 \\
10 & 40 & 200 & 50 & 4.64 & 52.5 & 72.0 & 4.1 & 0.5 & 5.1 & 9.7 & 3.6 & 17.9 & 64.6 \\
11 & 67 & 185 & 75 & 4.38 & 74.9 & 52.1 & 4.8 & 1.9 & 12.5 & 19.2 & 5.3 & 19.7 & 44.5 \\
12 & 50 & 160 & 75 & 3.64 & 81.3 & 47.8 & 4.7 & 2.2 & 11.1 & 18.0 & 4.6 & 23.8 & 27.2 \\
13 & 40 & 200 & 100 & 4.94 & 44.6 & 72.4 & 3.7 & 0.4 & 4.7 & 8.8 & 4.8 & 14.9 & 75.0 \\
14 & 60 & 200 & 100 & 4.94 & 59.9 & 60.5 & 4.6 & 0.3 & 11.3 & 16.2 & 5.6 & 17.1 & 61.5 \\
15 & 40 & 170 & 50 & 3.76 & 75.8 & 51.8 & 4.8 & 2.0 & 11.9 & 18.7 & 4.1 & 22.3 & 36.4 \\
16 & 50 & 185 & 117 & 4.57 & 60.9 & 59.0 & 4.1 & 0.6 & 11.5 & 16.2 & 4.5 & 14.4 & 67.0 \\
17 & 40 & 170 & 100 & 4.06 & 69.5 & 53.0 & 4.5 & 1.0 & 10.1 & 15.6 & 4.7 & 18.7 & 51.1 \\
\hline
\end{tabular}

$C_{E t O H}$, ethanol concentration; $S_{0}$, severity factor $\left(\mathrm{S}_{0}=\log (t \cdot \exp (T-100 / 14.75), t\right.$, time (min) and $T$, temperature $\left({ }^{\circ} \mathrm{C}\right)$ ); $Y_{\text {solid }}$, delignified solid yield; $G l$, glucan; $X$, xylan; $G a$, galactan; $M$, mannan; $H M C$, hemicellulose (sum of $\mathrm{X}, \mathrm{Ga}$, and $\mathrm{M}$ ); $S L$, soluble lignin; $I L$, insoluble lignin; $D D$, delignification degree 
is considered as the hemicellulose content (HMC). The delignification degree (DD) was calculated by the Eq. (2).

$D D(\%)=\frac{m_{\mathrm{ILpine}}-m_{\mathrm{ILsolid}}}{m_{\mathrm{ILpine}}} \cdot 100$

where $m_{\text {ILpine }}$ is the amount of insoluble lignin in the raw material ( $P$. radiata), and $m_{\mathrm{ILsolid}}$ is the amount of insoluble lignin in the delignified solid. Both are determined from these equations: $m_{\text {ILpine }}=\% I L_{\text {pine }} \cdot m_{\text {pine }}$ and $m_{\text {ILsolid }}=\% I L_{\text {solid }} \cdot m_{\text {solid }}$, being $m_{\text {pine }}$ the initial quantity of wood (20 g), $m_{\text {solid }}$ the quantity of delignified solid after organosolv process, $\% I L_{\text {pine }}$ the insoluble lignin content in the native wood, and $\% I L_{\text {solid }}$ the insoluble lignin content in the delignified solid. The delignification degree is an important response in the study of organosolv process to evaluate the extension of reaction [17, 37].

The thermal stability of delignified solids was determined by thermogravimetric analysis in a Mettler Toledo TGA/ DSC1. The temperature range employed was 30 to $900{ }^{\circ} \mathrm{C}$, using a heating rate of $10^{\circ} \mathrm{C} / \mathrm{min}$, and a dry nitrogen flow of $30 \mathrm{~mL} / \mathrm{min}$. For each experiment, delignified solid (8-9 mg) was charged into an alumina crucible $(70 \mu \mathrm{L})$. The parameters used to evaluate the effect of organosolv process on thermal stability of delignified solids were the temperature of $10 \%$ of the initial weight loss $\left(\mathrm{T}_{10 \%}\right)$ and the ash content at $800{ }^{\circ} \mathrm{C}$.

Fourier transform infrared spectroscopy (FTIR) of delignified solids was carried out in a spectrometer Jasco 4700 with Spectra Manager software to determine the structural changes in these solids after organosolv process. The solid samples in powder were mixed with $\mathrm{KBr}$ in a ratio 1:200 in an agate mortar. The resultant mixture was introduced in a manual hydraulic press at 7 ton and $30 \mathrm{~s}$ to obtain the pellet, which was analyzed in the absorbance range between 2000 and $800 \mathrm{~cm}^{-1}$, using $16 \mathrm{scans}$, and a resolution of $4 \mathrm{~cm}^{-1}$. In addition, a semiquantitive analysis was performed to determine the changes of bands. The ratio between absorbances was calculated using $1426 \mathrm{~cm}^{-1}$ as a reference band.

\subsection{Black liquor compositional analysis}

The liquid phase (black liquor) obtained after the organosolv process was analyzed by HPLC in order to quantify the hemicellulosic fraction of pine solubilized in form of sugars and degradation products. For this analysis, a ROA Organic Acid column (Phenomenex), $0.005 \mathrm{M} \mathrm{H}_{2} \mathrm{SO}_{4}$ as mobile-phase with a flow rate of $0.6 \mathrm{~mL} / \mathrm{min}$, and $60^{\circ} \mathrm{C}$ for column compartment temperature were employed. Xylose $(\mathrm{X})$, galactose $(\mathrm{Ga})$, and mannose $(\mathrm{M})$ were quantified as a single compound. The lignin dissolved in the black liquors was recovered by acid precipitation and characterized in a previous work [56].

\section{Results and discussion}

\subsection{Composition of Pinus radiata and delignified solids}

The raw material used in this study, $P$. radiata wood, presents the following chemical composition, expressed in oven-dry basis (wt $\%$ ): $43.8 \%$ glucan, $5.4 \%$ xylan, $3.1 \%$ galactan, $10.4 \%$ mannan, $2.3 \%$ arabinan, $26.6 \%$ insoluble lignin, 5.4\% soluble lignin, and 3.2\% extractives.

The data of chemical composition and delignification degree of delignified solid obtained for each run are also shown in Table 1. The responses that have given significant models are delignified $\mathrm{Y}_{\text {solid, }}$ Gl, HMC, and DD. The mathematical models with $R$-squared value are shown in Table 2, in which the effects with a significance level lower than $95 \%$ were neglected for regression models $(F>18.51$ and $P$-value $<0.05)$. The developed models for the responses present $R$-squared value between 94.39 and $97.86 \%$, which involves these models explained adequately in the data variation.

The delignified solid yield varied between 44.6 and $79.6 \%$ in the studied condition range (Table 1). These results can be compared with values of organosolv process of lignocellulosic materials, such as $43-83 \%$ for wheat straw [28] or 51-81\% for E. globulus wood [24]. Other authors obtained similar results in spite of using temperatures lower than those applied in this work, 36-81\% for barley straw [4], or $50-72 \%$ for $C$. Cardunculus [3]. However, sulfuric acid was employed as catalyst in these works. The variation of yield depends on different solubilization of lignin and hemicellulose in the liquid phase in function of experimental conditions. The increment of temperature and time resulted in
Table 2 Predictive models for organosolv process responses

\begin{tabular}{lc}
\hline Mathematic model & $R^{2}(\%)$ \\
\hline$Y_{\text {solid }}(\%)=310.473-2.14389 \mathrm{C}-1.40994 \mathrm{~T}-0.118115 \mathrm{t}+0.01425 \mathrm{CT}$ & 97.86 \\
$D D(\%)=-197.88+2.99284 \mathrm{C}+0.915013 \mathrm{~T}+0.221769 \mathrm{t}-0.0331703 \mathrm{C}^{2}$ & 94.39 \\
$H M C(\%)=-24.7489-0.420504 \mathrm{C}+0.677257 \mathrm{~T}-0.0262537 \mathrm{t}-0.0076506 \mathrm{C}^{2}+0.00783333 \mathrm{CT}$ & 97.06 \\
$-0.00332166 \mathrm{~T}^{2}$ & \\
$G l(\%)=87.6443+2.60086 \mathrm{C}-1.48763 \mathrm{~T}+0.0559885 \mathrm{t}-0.0159 \mathrm{CT}+0.00747852 \mathrm{~T}^{2}$ & 94.99 \\
\hline
\end{tabular}


the reduction of delignified solid yield due to the delignification and hemicellulose hydrolysis of native wood produced during the process. In this way, the increment of the severity from mild conditions $\left(170{ }^{\circ} \mathrm{C}\right.$ and $\left.50 \mathrm{~min}\right)$ to severe conditions $\left(200{ }^{\circ} \mathrm{C}\right.$ and $\left.100 \mathrm{~min}\right)$ supposes a reduction of delignified solid yield from 79 to 52\% (Fig. 1a). A reduction in alcohol concentration in solvent involves that solid yield decreases (Fig. 1b), because the higher water amount improves the hydrolysis of hemicellulose and, therefore, its loss of raw material [16]. Under $185^{\circ} \mathrm{C}$ and $75 \mathrm{~min}$ of pretreatment, the increment of ethanol concentration from 40 to $60 \%$ supposes an increase in delignified solid yield from ca. 60 to $70 \%$

The low delignified solid yields are obtained at the expense of high DD, as is exhibited in Fig. 2, where the linear relationship between DD and delignified solid yield is exhibited for all runs carried out. This trend was also obtained by Romaní et al. [17] and Weerasai et al. [19],

a)

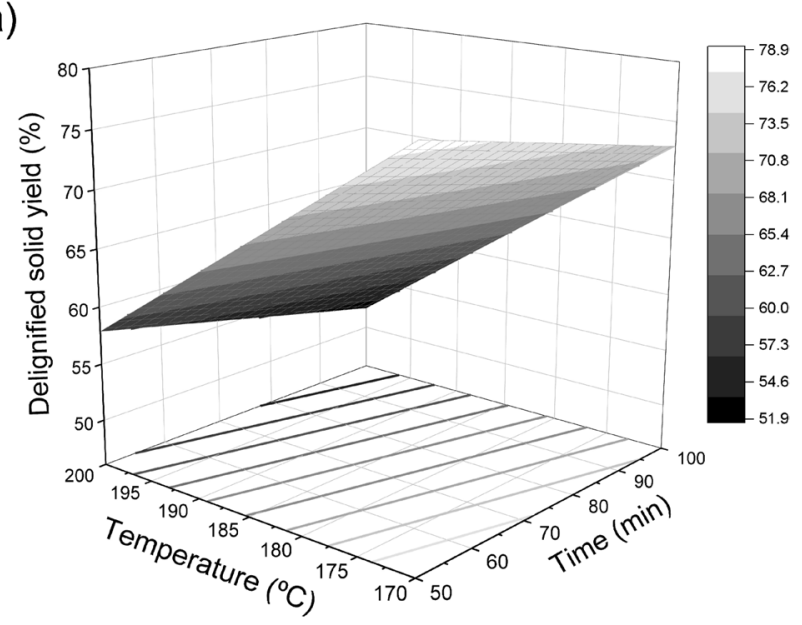

b)

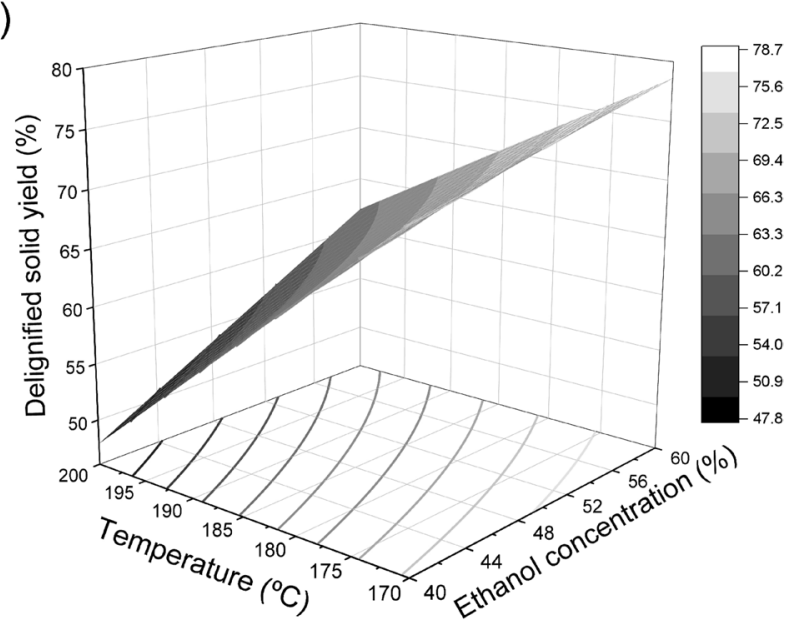

Fig. 1 The variation of delignified solid yield with two independent variables: a Temperature and time at $\mathrm{C}_{\mathrm{EtOH}}=50 \mathrm{wt} \%$, and $\mathbf{b}$ Temperature and ethanol concentration at $t=75 \mathrm{~min}$

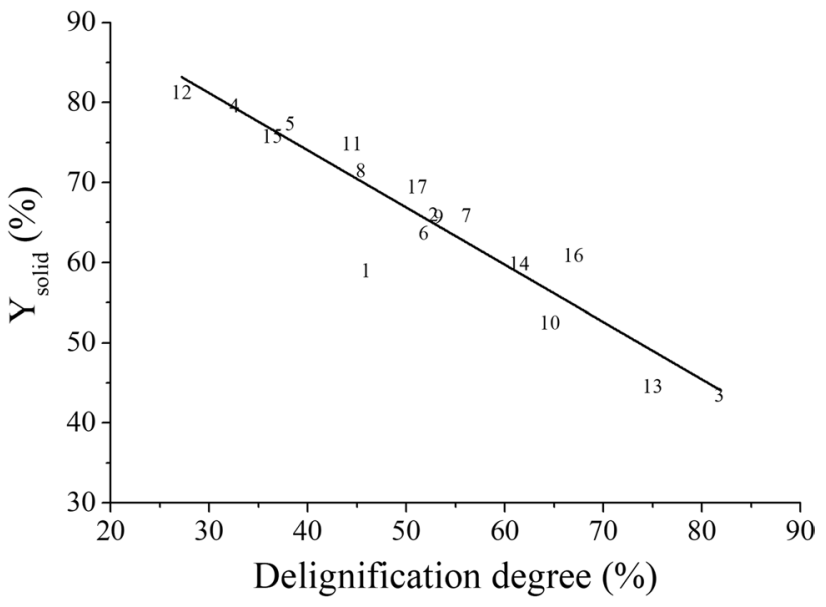

Fig. 2 Delignified solid yield vs delignified degree for each run from experimental design

whose lowest solid yields were achieved with the highest delignification, showing the inverse relationship between these responses. However, the run 1 presents a different behavior in Fig. 2. The solid obtained presented a low yield $(60 \%)$ with a low delignification degree $(46 \%)$. The drop of delignified solid yield is due to the high loss of hemicellulose obtained in this run, which was carried out with low ethanol concentration (33\%). Therefore, the hydrolysis of hemicellulose of pine is favored with the lower alcohol concentration and higher water concentration. The total HMC in delignified solid is $10.4 \%$ under these operating conditions (run no. 1). In the study of the HMC response, this trend is further detailed as shown the response surface plots.

The experimental results show that the DD values varied between 33 and $75 \%$ (Table 1). The increment of temperature and time has positive effect on the delignification of pine wood (Fig. 3a), which is in accordance with other lignocellulosic material results $[4,19]$. Under middle time condition (75 min), an increment of $30{ }^{\circ} \mathrm{C}$ in organosolv process means a DD increase of $\approx 23 \%$, from $41 \%$ at $170{ }^{\circ} \mathrm{C}$ to $68 \%$ at $200{ }^{\circ} \mathrm{C}$, whereas, under $185{ }^{\circ} \mathrm{C}$ fixed temperature, an increase of $50 \mathrm{~min}$ involves a rise of $\approx 11 \%$ in DD response, from $49 \%$ at $50 \mathrm{~min}$ to $60 \%$ at $100 \mathrm{~min}$ (Fig. 3a). At fixed value of $C_{\mathrm{EtOH}}=50 \mathrm{wt} \%$, the highest delignification degree $(D D=74 \%)$ is achieved at $200{ }^{\circ} \mathrm{C}$ and $100 \mathrm{~min}$ (Fig. 3a). These severe operating conditions for obtaining high delignification values are similar to those employed in others organosolv process carried out in absence of a catalyst, using ethanol/water as solvent and different raw materials. Romaní et al. [17] employed $200{ }^{\circ} \mathrm{C}, 90 \mathrm{~min}$, and $50 \%$ of ethanol for reaching $62.2 \%$ of delignification in E. nitens bark, and Wei et al. [32] achieved a lignin removal of 52.4\% in bagasse using $205^{\circ} \mathrm{C}, 30 \mathrm{~min}$, and $55 \%$ of ethanol. In this context, the use of severe conditions to achieve high lignin removal is also required in process without catalyst using 
a)

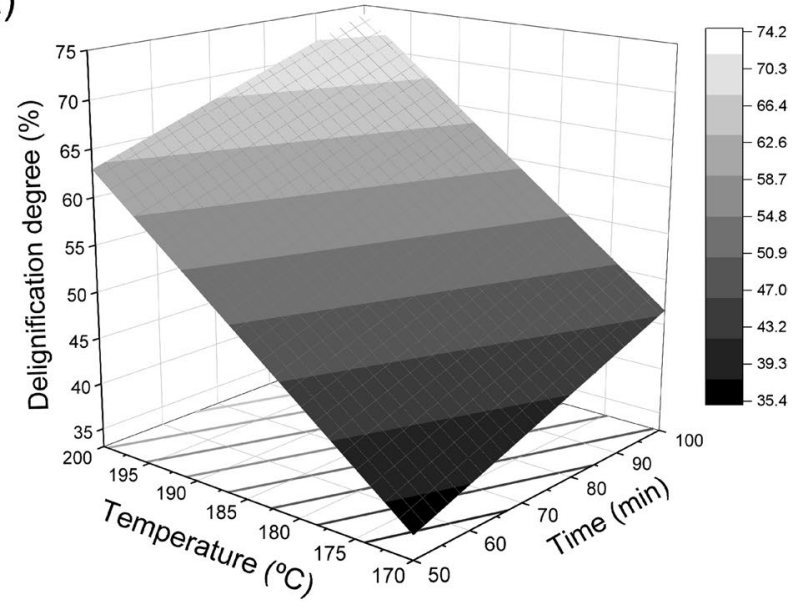

b)

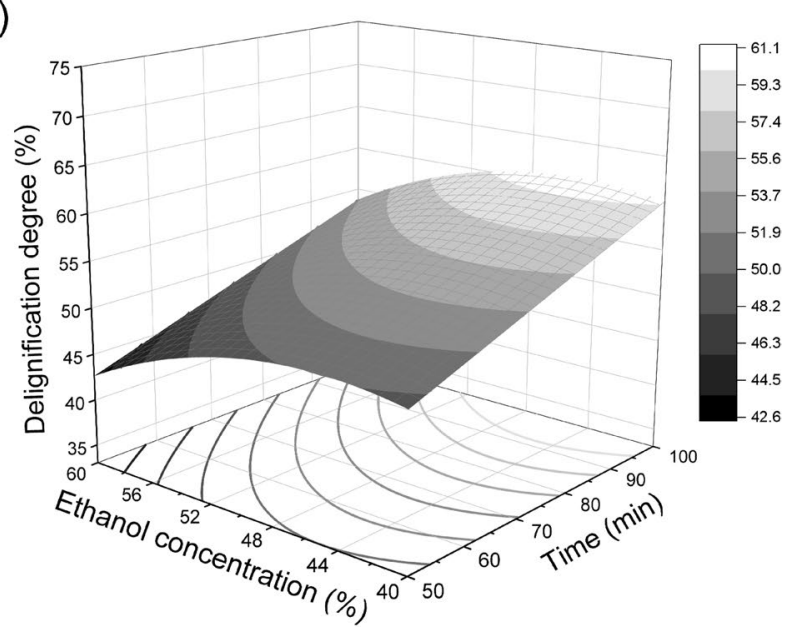

Fig. 3 The variation of delignification degree with two independent variables: a Temperature and time at $\mathrm{C}_{\mathrm{EtOH}}=50 \mathrm{wt} \%$, and b Ethanol concentration and time at $T=185^{\circ} \mathrm{C}$

other solvents, such as acetone or glycerol. Huijgen et al. [28] applied $205^{\circ} \mathrm{C}, 120 \mathrm{~min}$, and 50\% acetone to reach $79 \%$ of delignification in wheat straw, and Romaní et al. [24] reported $80 \%$ of delignification of E. globulus wood using $200{ }^{\circ} \mathrm{C},>58 \mathrm{~min}$, and $80 \%$ of glycerol.

The ethanol concentration in this autocatalyzed process has a relevant influence on delignification degree. The response surface plot of delignification degree for a constant temperature of $185^{\circ} \mathrm{C}$ is shown in Fig. 3b, where maximum delignification degree of $P$. radiata is achieved at $C_{\mathrm{EtOH}}=45$ $\mathrm{wt} \%$, and high times (>90 min). This result is likely a consequence of lignin degradation and lignin solubilization produced during organosolv process, which depend on the ethanol concentration. Lower ethanol concentration promotes the cleavage of $\alpha$ - and $\beta$-ether linkages in the lignin due to higher hydronium ion concentration; whereas, high alcohol concentration involves major solubilization of lignin [16, 35, 53]. In this work, the studied organosolv is an autocatalyzed a)

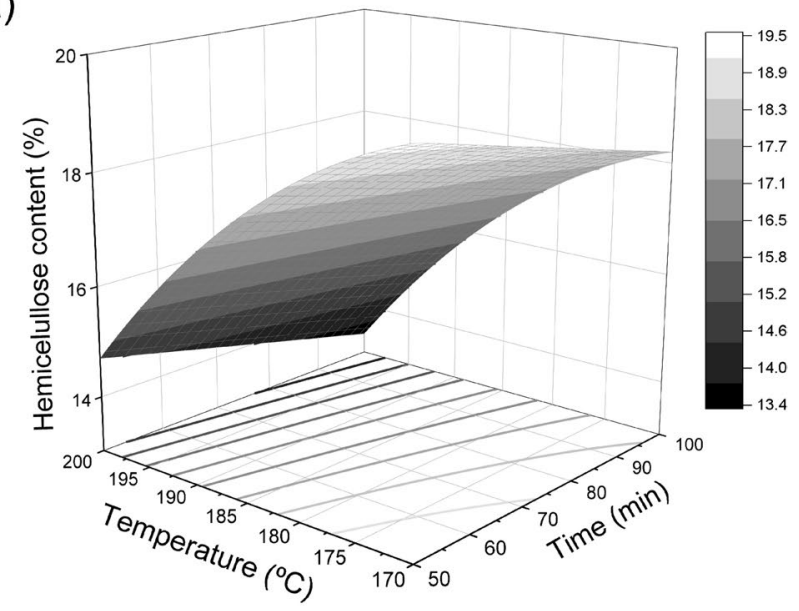

b)

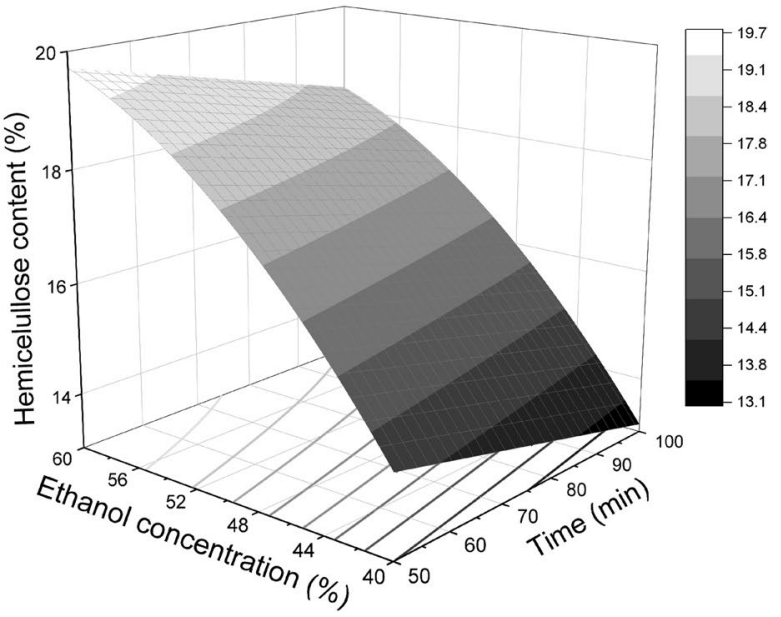

Fig. 4 The variation of hemicellulose content with two independent variables: a Temperature and time at $\mathrm{C}_{\mathrm{EtOH}}=50 \mathrm{wt} \%$, and b Ethanol concentration and time at $T=185^{\circ} \mathrm{C}$

process and, therefore, these effects only depend on ethanol concentration from initial mixture due to the absence of ions provided by catalyst. The maximum delignification is reached at $45 \mathrm{wt} \%$ of ethanol concentration, which is similar to the ones obtained by other authors studying solvent proportion in autocatalyzed process, such as $40 \mathrm{wt} \%$ required of acetone for wheat straw [28] or $40 \%$ (v/v) of ethanol for bagasse [32].

The elimination of lignin of $P$. radiata wood during the organosolv process is not exclusive, due to the hemicellulose, which is covalently linked to lignin and acts as the connection between lignin and cellulose, also being extracted [7]. The response surface plots of hemicellulose content (the sum of xylan, galactan, and mannan) are exhibited in Fig. 4. The hemicellulose content in delignified solids is in the range between 8.8 and $20.2 \%$ (Table 1). The temperature and time favor the hydrolysis and extraction of hemicellulose of $P$. radiata wood. Under $C_{\mathrm{EtOH}}=50 \mathrm{wt} \%$, reducing $\mathrm{HMC}$ 
percentage from $19.5\left(170{ }^{\circ} \mathrm{C}\right.$ and $\left.50 \mathrm{~min}\right)$ to $13.4 \%\left(200{ }^{\circ} \mathrm{C}\right.$ and $100 \mathrm{~min}$ ) was achieved (Fig. 4a). The ethanol concentration in the reaction medium has also great influence on HMC content of delignified solid, related to the water concentration. A higher hydronium ion concentration promotes the cleavage of hemicellulose bonds and, therefore, its loss from raw material. For this reason, under constant temperature of $185^{\circ} \mathrm{C}$ and $100 \mathrm{~min}$, the reduction of alcohol concentration from 60 to $40 \%$ involves a drop from 18.4 to $13 \%$ in HMC content (Fig. 4b). This hemicellulose hydrolysis reduction with organic solvent proportion has also been reported for organosolv of wheat straw employing acetone/water mixture [28].

In the studied range, the extraction of initial hemicellulose of $P$. radiata varied between 24 and $81 \%$. The high hemicellulose removal is also attributed to its amorphicity in comparison to cellulose [57]. A wide range of hemicellulose removal (16-88\%) was also found for ethanol-based organosolv of cardoon [3].

As a result of solubilization of lignin and hemicellulose, the delignified solids are enriched in cellulose (glucan). This response varied between 48 and $72 \%$ (Table 1). The response surface plots of glucan content at a constant ethanol concentration of $50 \mathrm{wt} \%$ and time of $75 \mathrm{~min}$ are exhibited in Fig. 5a and b, respectively. The pattern in previous studied responses (DD or HMC) is similar to those of glucan. The increment of time and temperature supposes the increase in glucan of delignified solid (Fig. $4 \mathrm{a}$ ), reaching $\approx 66 \%$ in glucan content under operating conditions of $200{ }^{\circ} \mathrm{C}$ and $100 \mathrm{~min}\left(C_{\mathrm{EtOH}}=50 \mathrm{wt} \%\right)$. The effect of high temperature is remarkable from $190{ }^{\circ} \mathrm{C}$, when the isolines are closer; a minor increment of temperature supposes the same increase of glucan content. At low ethanol concentrations, the glucan content is higher than of obtained at high ethanol concentration, due to the hydronium ion concentration as mentioned before. At fixed time of $75 \mathrm{~min}$ and $185{ }^{\circ} \mathrm{C}, 59 \%$ of glucan content is achieved under $40 \mathrm{wt} \%$ alcohol concentration, while this content is reduced to $52 \%$ when the initial ethanol concentration is $60 \mathrm{wt} \%$ (Fig. $4 \mathrm{~b}$ ). At $C_{\mathrm{EtOH}}=40 \mathrm{wt} \%$, a delignified solid with a glucan content $>66 \%$ is predicted by applying temperatures $>195{ }^{\circ} \mathrm{C}$ and times $>90 \mathrm{~min}$, supposing an enrichment of at least $50 \%$ respect to initial glucan content in P. radiata wood.

The amount of initial glucan of pine wood remains in delignified solid after organosolv process varying between 70 and $90 \%$. These values are close to other obtained woods under organosolv treatment, such as $75 \%$ obtained for Pinus contorta [35], 88\% for Populus nigra x P. maximowiczii [53], and 94\% for E. globulus [24]. The average amount of glucan lost during organosolv process is lower than $18 \%$. This fact is associated with amorphous regions of this polymer, which are more easily hydrolyzable [58]. Therefore, the organosolv process allows a)

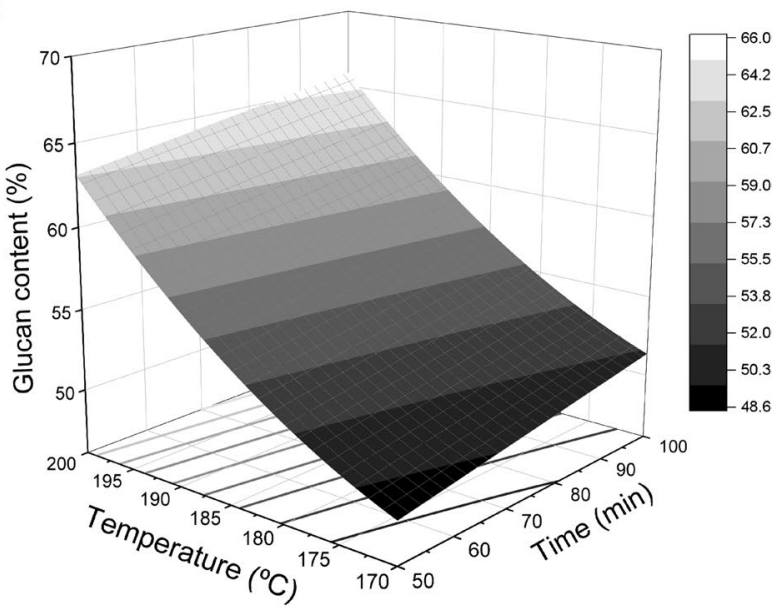

b)

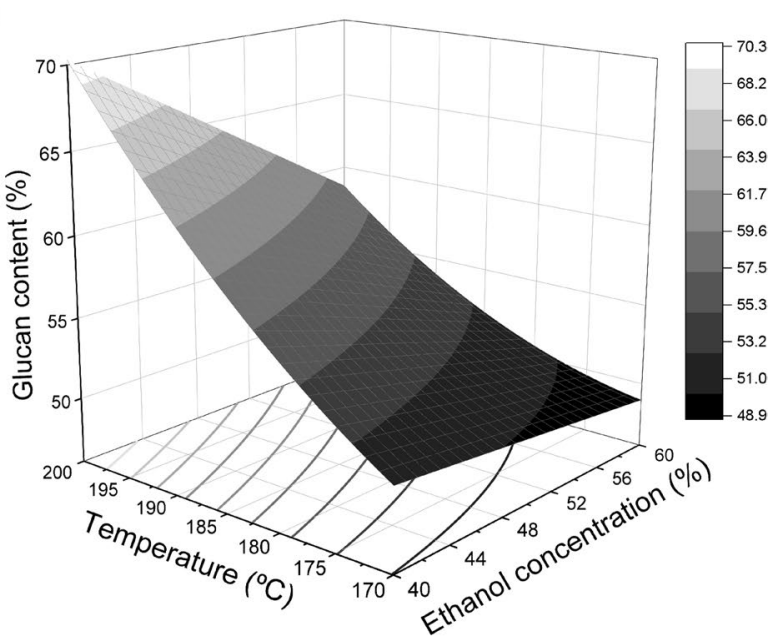

Fig. 5 The variation of glucan content with two independent variables: a temperature and time at $\mathrm{C}_{\mathrm{EtOH}}=50 \mathrm{wt} \%$, and $\mathbf{b}$ temperature and ethanol concentration at $t=75 \mathrm{~min}$

obtaining a cellulose-rich delignified solid under high temperatures and times, and low ethanol concentrations due to the extraction of lignin and hemicellulose fractions. A high glucan content (72\%) is achieved under operating conditions equal to $200{ }^{\circ} \mathrm{C}, 100 \mathrm{~min}\left(S_{0}=4.94\right)$ and 40 wt\% (run no. 13), involving a 1.65-fold increase of glucan content respect to initial pine wood. Note that the glucan recovery obtained under these severe conditions can be considered low (74\%). However, a low content of hemicellulose $(8.8 \%)$ and high delignification degree $(75 \%)$ are reached. This removal of hemicellulose and lignin of lignocellulosic materials is related to the improvement of the enzymatic hydrolysis $[7,15,45]$. Therefore, this solid rich in cellulose could be employed to obtain glucose or other added-value products, such as bioethanol, biohydrogen, or nanocellulose crystal [17, 38, 42]. 


\subsection{Thermal stability of delignified solids}

The TGA and DTG curves of four delignified solids (runs no. 3, 8, 12, and 16) are represented in Fig. 6. These solids were obtained under an ethanol concentration of $50 \mathrm{wt} \%$, and grouped as a function of fixed conditions, either $75 \mathrm{~min}$ of time (Fig. 6a) or $185{ }^{\circ} \mathrm{C}$ of temperature (Fig. 6b). In these thermograms, the temperature at which $10 \%$ initial weight is lost $\left(\mathrm{T}_{10 \%}\right)$ and the ash content at $800{ }^{\circ} \mathrm{C}$ are indicated. The higher $\mathrm{T}_{10 \%}$ values and lower ash contents are obtained under higher severity factors of organosolv process $\left(S_{0}=5.11\right.$ and $\left.S_{0}=4.57\right)$, as shown in Fig. 6. This fact means that the delignified solids obtained under severe conditions of organosolv process present higher thermal stability.

Regarding to the influence of temperature and time on thermal stability (Fig. 6), the increment of temperature pretreatment from 160 to $210{ }^{\circ} \mathrm{C}$ supposed an increase of $\approx 30{ }^{\circ} \mathrm{C}$ in $\mathrm{T}_{10 \%}$ value (no. 3 and no. $12, t=75 \mathrm{~min}$ ), whereas, under $185^{\circ} \mathrm{C}$ fixed temperature, the difference of $\mathrm{T}_{10 \%}$ values was $\approx 15{ }^{\circ} \mathrm{C}$ when the organosolv time was increased (no. 8 and no. 16). Thus, the TGA results show that the temperature and time have a positive effect on thermal stability of delignified solids because the higher these conditions are, the higher $\mathrm{T}_{10 \%}$ values are. Besides, the influence of temperature is greater than of time. On the other hand, the low residual contents of delignified solids (19-25\%) can be attributed to low lignin content remained after organosolv process $[23,41]$. This fact is according to high delignification degree values obtained for these runs (Section 3.1). For example, run no. 3 achieved a DD equal of $82 \%$ and presented the lowest ash content (19\%), while run no. 12, whose DD was $27 \%$, presented an ash content of $25 \%$.

Respect to DTG curves, run no. 3 presents a clear peak, which can be related to high cellulose content in delignified solid (71\%), while the rest of DTG curves exhibit an unsymmetrical peak due to the presence of hemicellulose and lignin [41]. The degradation of three polymers presented in delignified solids is overlapped in this unsymmetrical peak shown by runs no. 8,12 , and 16 (Fig. 6). The degradation of hemicellulose takes place between 220 and $315^{\circ} \mathrm{C}$, while a)
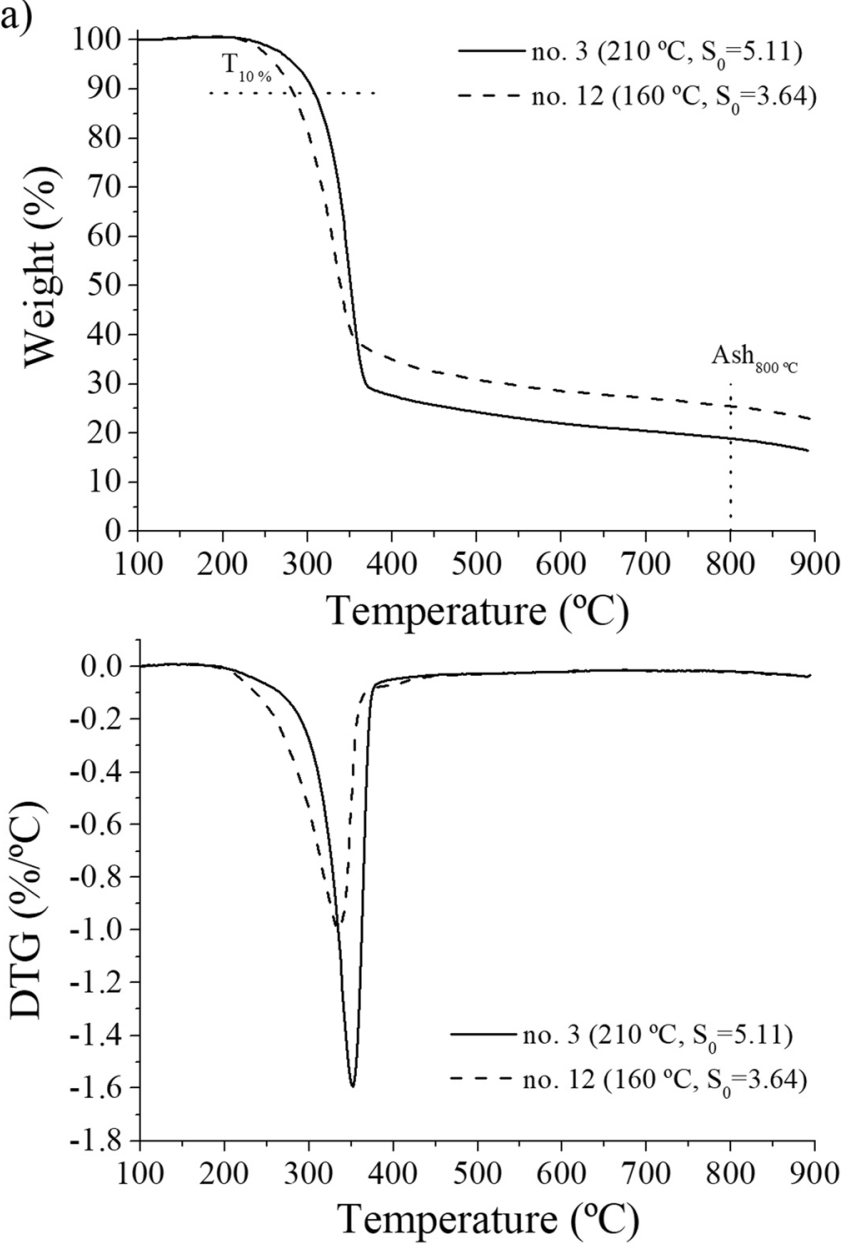

b)
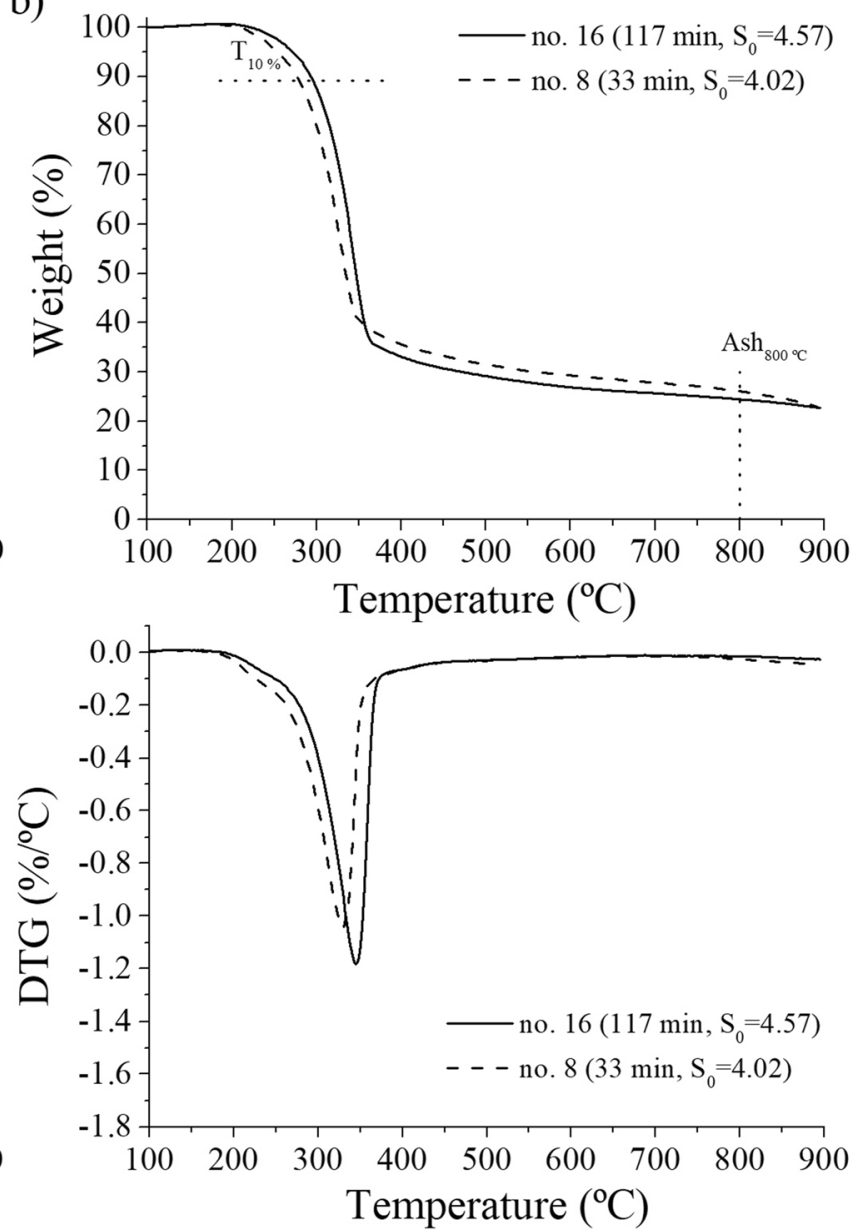

Fig. 6 TGA and DTG curves of the delignified solids obtained at $\mathrm{C}_{\mathrm{EtOH}}=50 \mathrm{wt} \%$ : a $t=75 \mathrm{~min}$, and $\mathbf{b} T=185^{\circ} \mathrm{C}$ 


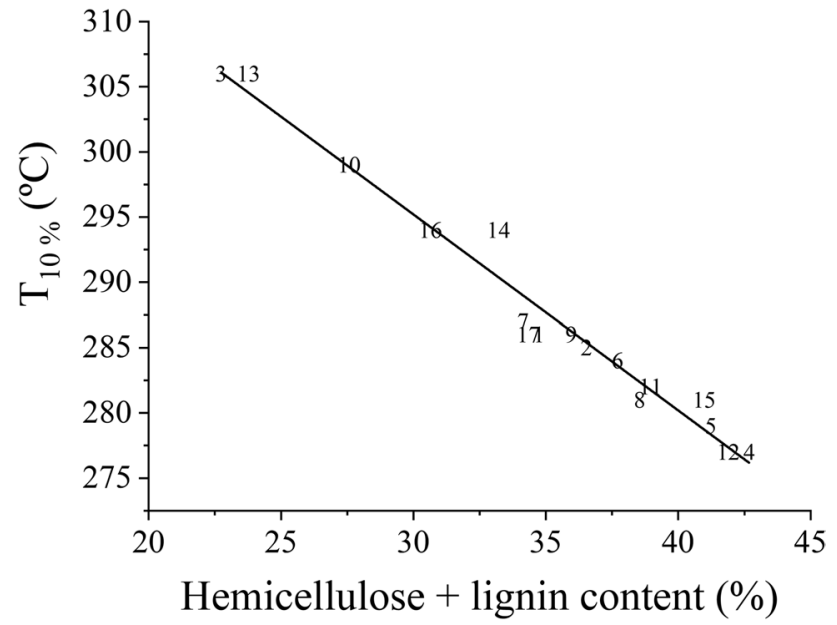

Fig. 7 Relationship between $\mathrm{T}_{10 \%}$ and hemicellulose + lignin content (\%) in delignified solids

cellulose does between 315 and $400{ }^{\circ} \mathrm{C}$. Lignin presents a broader range of degradation between 200 and $480{ }^{\circ} \mathrm{C}$ [59]. For this reason, the weight loss of delignified solids with higher hemicellulose content begins at lower temperatures than those solids with lower hemicellulose content (Fig. 6). Therefore, DTG curves show the dependence of the thermal stability of delignified solids on their chemical compositions.

$\mathrm{T}_{10 \%}$ of all samples from experimental design has been represented as a function of the sum of hemicellulose and lignin content in delignified solids (Fig. 7). There is a clear trend between these responses; $\mathrm{T}_{10 \%}$ increased linearly with decreasing the hemicellulose and lignin content. Thus, the hemicellulose + lignin content of delignified solid under mild conditions (no. $4,60 \mathrm{wt} \%, S_{0}=3.76$ ) was $42.6 \%$ corresponding to $\mathrm{T}_{10 \%}$ of $277{ }^{\circ} \mathrm{C}$, whereas, this content was reduced until $23.7 \%$, increasing $\mathrm{T}_{10 \%}$ until $306^{\circ} \mathrm{C}$, by applying severe conditions (no. 13, $40 \mathrm{wt} \%, S_{0}=4.94$ ). The increment of thermal stability of delignified solids can be attributed to the removal of these polymers and, therefore, the increase of cellulose (glucan) content occurred during the process [45]. This is similar to the results obtained from the other lignocellulosic materials, such as wheat straw and sugarcane bagasse, in which the degradation 20 and $50 \%$ of samples treated by organosolv was achieved at higher temperatures than that of raw materials. For instance, the temperature at which wheat straw degraded $20 \%$ was increased from 264 to $337^{\circ} \mathrm{C}$ when an organosolv was carried out by employing $220{ }^{\circ} \mathrm{C}, 3 \mathrm{~h}$, and $70 \%$ aqueous glycerol [23, 44]. Thus, the TGA and DTG results confirm that cellulose remains in delignified solids after organosolv process, while other fractions of $P$. radiata wood are removed, and reveal the relationship between the thermal stability of this cellulose-rich delignified solid and its lignin and hemicellulose content.

\subsection{Structural changes of delignified solids}

The FTIR spectra of the delignified solids obtained at different severity factors and ethanol concentrations, corresponding to maximum and minimum values of experimental design, are exhibited in Fig. 8. The main changes observed in the spectra are related to hemicellulose and lignin bands, which are the polymers removed during organosolv process. The band $1735 \mathrm{~cm}^{-1}$ corresponds to acetyl groups in hemicellulose [60]. This band is weaker when severity factor is increased due to the reduction of hemicellulose content in delignified solids, as confirmed in compositional analysis (Section 3.1). For instance, in the delignified solid from run no. 4 , which presents a HMC content of $20.2 \%$, the band at $1735 \mathrm{~cm}^{-1}$ is more defined than that of the delignified solid from run no. 13, whose HMC content is $8.8 \%$ and, therefore, this band is not appreciated. The semicuantitative analysis confirms this trend; a reduction in the ratio $\mathrm{A}_{1735} / \mathrm{A}_{1426}$ from 0.9208 to 0.8061 with the increment from $S_{0}=3.76$ to $S_{0}=4.94$ was observed, at $C_{\mathrm{EtOH}}=60 \mathrm{wt} \%$ (no. 4 and no. 14 ).

The characteristic bands of lignin also reduced its intensity gradually as a consequence of the severity factor increment in organosolv process. These bands correspond to aromatic skeletal vibration breathing with $\mathrm{C}=\mathrm{O}$ stretching $\left(1596 \mathrm{~cm}^{-1}\right)$, aromatic skeletal vibration $\left(1512 \mathrm{~cm}^{-1}\right)$, and guaiacyl ring breathing with $\mathrm{C}=\mathrm{O}$ stretching $\left(1267 \mathrm{~cm}^{-1}\right)$ [61]. The reduction of these bands is due to the delignification occurred in the process, and can be related to delignification degree. For example, the ratio $\mathrm{A}_{1512} / \mathrm{A}_{1426}$ in samples no. 13 and no. 15 was reduced from 0.3085 to 0.2322 , corresponding to the increment of DD from 36.4 to $75 \%$.

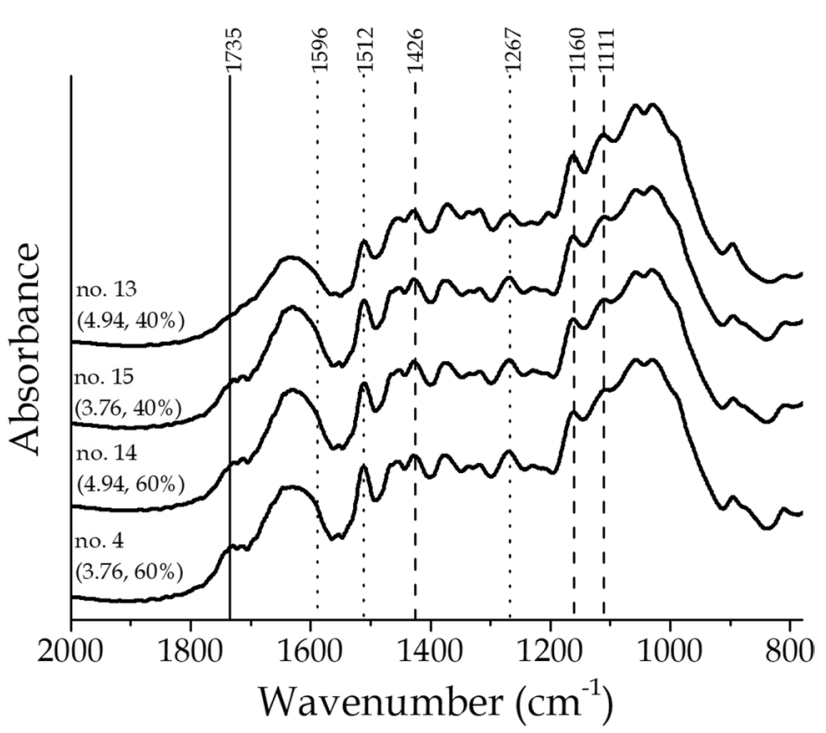

Fig. 8 FTIR spectra of delignified solids obtained from runs no 4, 13, 14 , and 15 
According to the enrichment in cellulose (glucan) of delignified solids, the cellulose bands incremented its intensity with the increase of the severity factor of organosolv process. These bands correspond with $\mathrm{C}-\mathrm{O}-\mathrm{C}$ stretching asymmetric $\left(1160 \mathrm{~cm}^{-1}\right)$, and glucose ring stretching asymmetric $\left(1111 \mathrm{~cm}^{-1}\right)$ [62]. Other authors have observed similar changes in FTIR spectra after organosolv process, employing different solvents and raw materials, such as bagasse [15, 29, 32], wheat straw [23, 37], corn stover [22], or hybrid Pennisetum grass [45]. Therefore, the FTIR analysis confirms the loss of hemicellulose and lignin of pine wood produced during ethanol-based organosolv process, depending on experimental conditions. This trend is according to the delignified solid composition and delignification degree previously calculated (Section 3.1).

\subsection{Black liquor composition}

The $\mathrm{pH}$ value and sugar and degradation product concentration of the black liquor of the seventeen experiments carried out in the experimental design are shown in Table 3.

The $\mathrm{pH}$ values of the black liquors ranged between 3.8 and 5.1. These values are similar to the achieved organosolv liquid phase of other lignocellulosic materials, such as E. globulus or wheat straw, using also an ethanol/water mixture as solvent $[10,16]$. Under the alcohol concentration $C_{\mathrm{EtOH}}=40 \mathrm{wt} \%$, the lowest $\mathrm{pH}$ value corresponds to the highest severity factor of organosolv process $(\mathrm{pH}=3.78$, $S_{0}=4.94$ ). This behavior can be explained by the hydrolysis and solubilization of hemicellulose in the black liquors.
A higher hemicellulose hydrolysis involves the higher formation of acetic acid from acetyl groups. The run no. 13 $\left(S_{0}=4.94\right)$, which presented a low HMC content in delignified solid (8.8\%), reached an acetic acid concentration in the black liquor of $2.66 \mathrm{~g} / \mathrm{L}$, and the lowest $\mathrm{pH}$ value (3.78). In addition, the solubilized hemicellulose can be degraded into organic acid, such as formic acid (FA), as shown in Table 3. The release of both acids contributes to the $\mathrm{pH}$ value drop of the reaction medium.

These results are in accordance with the concentration of sugars and degradation products quantified in the black liquors (Table 3 ). The release of glucose (Gl), xylose + mannose + galactose $(\mathrm{X}-\mathrm{M}-\mathrm{Ga})$, and arabinose (A) agrees with the loss of hemicellulosic and cellulosic fraction of delignified solid. The glucose concentration is lower than that of the other sugars, due to the minor degradation of glucan of the raw material during the organosolv process, as commented before (Section 3.1). The maximum values of glucose concentration are 1.07 and $1.09 \mathrm{~g} / \mathrm{L}$, which are obtained under high organosolv temperature $\left(200{ }^{\circ} \mathrm{C}\right)$. This limited glucan hydrolysis during the organosolv is consistent with the results obtained by other authors using diverse raw materials such as wheat straw [28], empty palm fruit bunch [54], bagasse [32], or E. nitens bark [17]. According to the extraction of hemicellulose of $P$. radiata during ethanol-based organosolv, the hemicellulose-derived sugars in black liquors increased with temperature and time (severity factor). These results are similar to the findings in the Oxiorganosolv of beech wood, in which the hemicellulose recovery
Table 3 Experimental results for $\mathrm{pH}$, and sugars, and degradation product concentration of black liquors $(\mathrm{g} / \mathrm{L})$

\begin{tabular}{lllllllll}
\hline Run & $\mathrm{pH}$ & $\mathrm{Gl}$ & $\mathrm{X}-\mathrm{M}-\mathrm{Ga}$ & $\mathrm{A}$ & $\mathrm{FA}$ & $\mathrm{AA}$ & HMF & $\mathrm{F}$ \\
\hline 1 & 3.90 & 0.38 & 1.41 & 0.76 & 0.49 & 0.76 & 0.21 & 0.17 \\
2 & 4.64 & 0.12 & 0.35 & 0.51 & 0.55 & 1.04 & 0.03 & 0.02 \\
3 & 4.01 & 0.49 & 1.11 & 0.33 & 0.49 & 1.34 & 0.92 & 0.07 \\
4 & 5.08 & - & 0.15 & 0.90 & 0.19 & 0.36 & - & 0.01 \\
5 & 4.84 & - & 0.14 & 0.77 & 0.24 & 0.42 & 0.06 & 0.01 \\
6 & 4.42 & 0.04 & 0.31 & 0.58 & 0.30 & 0.52 & 0.12 & 0.04 \\
7 & 4.42 & 0.03 & 0.35 & 0.51 & 0.26 & 0.45 & 0.15 & 0.08 \\
8 & 4.48 & 0.02 & 0.24 & 0.84 & 0.20 & 0.35 & 0.10 & 0.01 \\
9 & 4.49 & 0.03 & 0.35 & 0.67 & 0.32 & 0.55 & 0.16 & 0.02 \\
10 & 3.93 & 1.07 & 3.62 & 0.63 & 0.41 & 0.12 & 1.33 & 0.03 \\
11 & 4.68 & 0.01 & 0.16 & 0.55 & 0.25 & 0.62 & 0.19 & 0.01 \\
12 & 4.63 & 0.02 & 0.10 & 0.70 & 0.18 & 0.32 & 0.06 & - \\
13 & 3.78 & 1.09 & 2.80 & 0.89 & 1.52 & 2.66 & 1.58 & 0.08 \\
14 & 4.40 & 0.33 & 0.70 & 0.35 & 0.74 & 1.39 & 0.46 & 0.04 \\
15 & 4.30 & 0.09 & 0.27 & 0.97 & 0.28 & 0.42 & 0.13 & 0.01 \\
16 & 4.42 & 0.22 & 0.76 & 0.75 & 0.72 & 1.21 & 0.26 & 0.02 \\
17 & 4.32 & 0.11 & 0.53 & 1.03 & 0.53 & 0.53 & 0.16 & 0.03 \\
\hline
\end{tabular}

$G l$, glucose; $X-M-G a$, xylose + mannose + galactose; $A$, arabinose; $F A$, formic acid; $A A$, acetic acid; $H M F$, hydroxymethylfurfural; $F$, furfural 
in liquid fraction was higher when pretreatment temperature and cooking time increased. For example, the increment of time from 60 to $120 \mathrm{~min}$ supposed the increase of hemicellulose recovery in liquor from 16.0 to $33.4 \%$, while the temperature increase from 150 to $175{ }^{\circ} \mathrm{C}$ involved a rise from 33.4 to $76.2 \%$ [43]. The hemicellulose hydrolysis is autocatalyzed by acetic acid (AA) released from acetyl groups [28]. Thus, the increase of severity factor from $S_{0}=3.76$ to $S_{0}=4.94$ supposed a rise from 0.15 to $0.70 \mathrm{~g} / \mathrm{L}$ in X-M-Ga concentration (60 wt\%, runs no. 4 and no. 14). However, the reduction of $\mathrm{C}_{\mathrm{EtOH}}$ from 60 to $40 \mathrm{wt} \%$ involves an increment of sugar concentration from 0.70 to $2.80 \mathrm{~g} / \mathrm{L}$ for the same severity factor $\left(S_{0}=4.94\right.$, runs no. 13 and no. 14). This behavior is justified by the increment of hydronium ion concentration, which favors the hydrolysis of hemicellulose, when the alcohol concentration is lower, as mentioned before. The highest value of $\mathrm{X}-\mathrm{M}-\mathrm{Ga}$ concentration is detected in run no. $10(3.62 \mathrm{~g} / \mathrm{L})$, when severe conditions were applied $\left(200^{\circ} \mathrm{C}, 50 \mathrm{~min}\right.$, and $C_{\mathrm{EtOH}}=40 \%$ ). However, the increment of time from 50 to 100 min supposes the concentration reduction to $2.80 \mathrm{~g} / \mathrm{L}$ (run no. 13), due to the degradation to furans. Thus, the hydroxymethylfurfural concentration was incremented from 1.33 to $1.58 \mathrm{~g} / \mathrm{L}$ (runs no. 10 and 13).

Regarding the formation of furan byproducts, the hydroxymethylfurfural (HMF) concentration is higher than furfural (F) in all studied range. This fact is attributed to the HMF that comes from the degradation of the hexoses which mainly composed the raw material employed, a softwood ( $P$. radiata). Unlike hardwood or herbaceous plants, whose major hemicelluloses are xylans, the main hemicelluloses in softwood are galactoglucomannans [8]. The effect of organosolv conditions on the furan formation is similar to other response, such as $\mathrm{pH}$ or monomeric sugars. The increase of temperature and time promotes the formation of furans from hemicellulose and cellulose fractions solubilized in the black liquor [54].The HMF and furfural concentrations are increased from 0.13 and $0.01 \mathrm{~g} / \mathrm{L}$ to 1.58 and $0.08 \mathrm{~g} / \mathrm{L}$, respectively, when the severity factor increased from $S_{0}=3.76$ to $S_{0}=4.94$, at $C_{\mathrm{EtOH}}=40$ wt\% (runs no. 13 and no. 15). In contrast, under the same severity factor $\left(S_{0}=4.06\right.$, runs no. 4 and no. 17$)$, when the alcohol concentration in solvent is increased from 40 to $60 \mathrm{wt} \%$, these concentrations are reduced from 0.16 and $0.03 \mathrm{~g} / \mathrm{L}$ to 0.06 and $0.01 \mathrm{~g} / \mathrm{L}$, respectively. These trends agree with those found by Wei et al. [32], who carried out an autocatalyzed organosolv process for bagasse. In this study, the increment of ethanol content from 25 to $70 \%(\mathrm{v} / \mathrm{v})$ involved the decrease in HMF and furfural concentration from 1.38 and $0.41 \mathrm{~g} / \mathrm{L}$ to 0.25 and $0.03 \mathrm{~g} / \mathrm{L}$, respectively. In the same way, the use of other mixture in autocatalyzed organosolv such as acetone/water achieved similar results, in which an increase of acetone content supposed the reduction of furan concentration in black liquors [28].

These results show the hemicellulosic fraction of $P$. radiata wood, solubilized during organosolv process, remains in black liquors after the recovery of lignin, carried out via precipitation in our previous work [56]. This stream with hemicellulose from lignocellulosic materials has shown its potential to be valorized in several applications [21, 50, 52]. For instance, furan (furfural and hydroxymethylfurfural) production has been recently proposed by acidic treatment of this stream [20].

\section{Conclusions}

An autocatalyzed organosolv process was investigated to fractionate a softwood, $P$. radiata, by employing a central composite design. The increment of temperature and time showed positive influence on the delignification and hemicellulose hydrolysis of pine and, therefore, improved the glucan content of delignified solid, but involved the solid yield reduction. However, the increase of ethanol concentration supposed the opposite trend of these responses, except on delignification, whose maximum was achieved at $C_{\mathrm{EtOH}}=45$ $\mathrm{wt} \%$. On average, more than $80 \%$ of initial cellulose of pine was recovered in delignified solid in studied operating conditions. At least $50 \%$ of glucan enrichment respect initial wood can be achieved by employing of $\mathrm{T}>195{ }^{\circ} \mathrm{C}$ and $\mathrm{t}>90 \mathrm{~min}$, at $C_{\mathrm{EtOH}}=40 \mathrm{wt} \%$, involving a glucan content of more than $66 \%$ in delignified solid. The inverse relationship between the hemicellulose and lignin content of delignified solid and its thermal stability was revealed from TGA analysis. The lignin and hemicellulosic fractions solubilized during the organosolv process were recovered in black liquors. The efficient separation of compounds, which could be used as feedstock for value-added chemical production, allows the valorization of $P$. radiata wood.

Funding Open Access funding provided thanks to the CRUE-CSIC agreement with Springer Nature. The authors are grateful to Ministerio de Economía y Competitividad (Project CTQ2017-88623R) and Comunidad de Madrid (Project P2018/EMT-4348 (SUSTEC-CM)) for financial support.

\section{Declarations}

Conflict of interest The authors declare no competing interests.

Open Access This article is licensed under a Creative Commons Attribution 4.0 International License, which permits use, sharing, adaptation, distribution and reproduction in any medium or format, as long as you give appropriate credit to the original author(s) and the source, provide a link to the Creative Commons licence, and indicate if changes 
were made. The images or other third party material in this article are included in the article's Creative Commons licence, unless indicated otherwise in a credit line to the material. If material is not included in the article's Creative Commons licence and your intended use is not permitted by statutory regulation or exceeds the permitted use, you will need to obtain permission directly from the copyright holder. To view a copy of this licence, visit http://creativecommons.org/licenses/by/4.0/.

\section{References}

1. Phi Trinh LT, Lee J-W, Lee H-J (2016) Acidified glycerol pretreatment for enhanced ethanol production from rice straw. Biomass bioenergy 94:39-45. https://doi.org/10.1016/j.biombioe.2016.08. 017

2. Sun S, Sun S, Cao X, Sun R (2016) The role of pretreatment in improving the enzymatic hydrolysis of lignocellulosic materials. Bioresour Technol 199:49-58. https://doi.org/10.1016/j.biortech. 2015.08.061

3. Vergara P, Ladero M, García-Ochoa F, Villar JC (2018) Valorization of Cynara Cardunculus crops by ethanol-water treatment: optimization of operating conditions. Ind Crops Prod 124:856862. https://doi.org/10.1016/J.INDCROP.2018.08.064

4. Salapa I, Topakas E, Sidiras D (2018) Simulation and optimization of barley straw organosolv pretreatment. Ind Crops Prod 113:80-88. https://doi.org/10.1016/j.indcrop.2018.01.018

5. Jatoi AS, Abbasi SA, Hashmi Z, Shah AK, Alam MS, Bhatti ZA, Maitlo G, Hussain S, Khandro GA, Usto MA (2021) Recent trends and future perspectives of lignocellulose biomass for biofuel production: a comprehensive review. Biomass Convers Biorefin. https://doi.org/10.1007/s13399-021-01853-8

6. Das N, Jena PK, Padhi D, Mohanty MK, Sahoo G (2021) A comprehensive review of characterization, pretreatment and its applications on different lignocellulosic biomass for bioethanol production. Biomass Convers Biorefin. https://doi.org/10.1007/ s13399-021-01294-3

7. Zhang Z, Harrison MD, Rackemann DW, Doherty WO, O'Hara IM (2016) Organosolv pretreatment of plant biomass for enhanced enzymatic saccharification. Green Chem 18(2):360-381. https:// doi.org/10.1039/C5GC02034D

8. Nitsos C, Rova U, Christakopoulos P (2018) Organosolv fractionation of softwood biomass for biofuel and biorefinery applications. Energies 11(1):50. https://doi.org/10.3390/en11010050

9. Ferreira JA, Taherzadeh MJ (2020) Improving the economy of lignocellulose-based biorefineries with organosolv pretreatment. Bioresour Technol 299:122695. https://doi.org/10.1016/j.biortech. 2019.122695

10. Oliet M, García J, Rodríguez F, Gilarranz MA (2002) Solvent effects in autocatalyzed alcohol-water pulping: comparative study between ethanol and methanol as delignifying agents. Chem Eng J 87(2):157-162. https://doi.org/10.1016/S1385-8947(01)00213-3

11. Salapa I, Katsimpouras C, Topakas E, Sidiras D (2017) Organosolv pretreatment of wheat straw for efficient ethanol production using various solvents. Biomass bioenergy 100:10-16. https://doi. org/10.1016/j.biombioe.2017.03.011

12. Marks C, Viell J (2021) Acetosolv pretreatment of wood for biorefinery applications. Biomass Convers Biorefin. https://doi.org/10. 1007/s13399-021-02023-6

13. Soltaninejad A, Jazini M, Karimi K (2021) Sustainable bioconversion of potato peel wastes into ethanol and biogas using organosolv pretreatment. Chemosphere:133003. https://doi.org/10. 1016/j.chemosphere.2021.133003

14. Jang S-K, Kim H-Y, Jeong H-S, Kim J-Y, Yeo H, Choi I-G (2016) Effect of ethanol organosolv pretreatment factors on enzymatic digestibility and ethanol organosolv lignin structure from Liriodendron tulipifera in specific combined severity factors. Renew Energy 87. Part 1:599-606. https://doi.org/10.1016/j.renene.2015. 10.045

15. Zhang H, Wu S (2015) Generation of lignin and enzymatically digestible cellulose from ethanol-based organosolv pretreatment of sugarcane bagasse. Cellulose 22(4):2409-2418. https://doi.org/ 10.1007/s10570-015-0678-Z

16. Wildschut J, Smit AT, Reith JH, Huijgen WJJ (2013) Ethanolbased organosolv fractionation of wheat straw for the production of lignin and enzymatically digestible cellulose. Bioresour Technol 135:58-66. https://doi.org/10.1016/j.biortech.2012.10.050

17. Romaní A, Larramendi A, Yáñez R, Cancela Á, Sánchez Á, Teixeira JA, Domingues L (2019) Valorization of Eucalyptus nitens bark by organosolv pretreatment for the production of advanced biofuels. Ind Crops Prod 132:327-335. https://doi.org/10.1016/j. indcrop.2019.02.040

18. Bär J, Phongpreecha T, Singh SK, Yilmaz MK, Foster CE, Crowe JD, Hodge DB (2018) Deconstruction of hybrid poplar to monomeric sugars and aromatics using ethanol organosolv fractionation. Biomass Convers Biorefin 8(4):813-824. https://doi.org/10. 1007/s13399-018-0330-x

19. Weerasai K, Laosiripojana N, Imman S, Kreetachat T, Suriyachai N (2021) Reusable alkaline catalyzed organosolv pretreatment and delignification of bagasse for sugar platform biorefinery. Biomass Convers Biorefin. https://doi.org/10.1007/s13399-020-01269-w

20. Rivas S, López L, Vila C, Parajó JC (2021) Organosolv processing of vine shoots: fractionation and conversion of hemicellulosic sugars into platform chemicals by microwave irradiation. Bioresour Technol 342:125967. https://doi.org/10.1016/j.biortech.2021. 125967

21. Teramura H, Sasaki K, Oshima T, Kawaguchi H, Ogino C, Sazuka T, Kondo A (2018) Effective usage of sorghum bagasse: optimization of organosolv pretreatment using 25\% 1-butanol and subsequent nanofiltration membrane separation. Bioresour Technol 252:157-164. https://doi.org/10.1016/j.biortech.2017.12.100

22. Xue F, Li W, An S, Li C, Li X, Wu M, Wei X (2021) Ethylene glycol based acid pretreatment of corn stover for cellulose enzymatic hydrolysis. RSC Adv 11(23):14140-14147. https://doi.org/ 10.1039/D0RA10877D

23. Sun FF, Wang L, Hong J, Ren J, Du F, Hu J, Zhang Z, Zhou B (2015) The impact of glycerol organosolv pretreatment on the chemistry and enzymatic hydrolyzability of wheat straw. Bioresour Technol 187:354-361. https://doi.org/10.1016/j.biortech. 2015.03.051

24. Romaní A, Ruiz HA, Pereira FB, Domingues L, Teixeira JA (2013) Fractionation of Eucalyptus globulus wood by glycerolwater pretreatment: optimization and modeling. Ind Eng Chem Res 52(40):14342-14352. https://doi.org/10.1021/ie402177f

25. Snelders J, Dornez E, Benjelloun-Mlayah B, Huijgen WJJ, de Wild PJ, Gosselink RJA, Gerritsma J, Courtin CM (2014) Biorefining of wheat straw using an acetic and formic acid based organosolv fractionation process. Bioresour Technol 156:275-282. https://doi.org/10.1016/j.biortech.2014.01.069

26. Zhao X, Liu D (2012) Fractionating pretreatment of sugarcane bagasse by aqueous formic acid with direct recycle of spent liquor to increase cellulose digestibility-the Formiline process. Bioresour Technol 117:25-32. https://doi.org/10.1016/j.biortech.2012. 04.062

27. Pathak P, Gupta A, Bhardwaj NK, Goyal A, Moholkar VS (2020) Impact of mild and harsh conditions of formic acid-based organosolv pretreatment on biomass fractionation of sugarcane tops. Biomass Convers Biorefin 11:2027-2040. https://doi.org/10.1007/ s13399-020-00629-w

28. Huijgen WJJ, Reith JH, den Uil H (2010) Pretreatment and fractionation of wheat straw by an acetone-based organosolv process. 
Ind Eng Chem Res 49(20):10132-10140. https://doi.org/10.1021/ ie $101247 \mathrm{w}$

29. Singh S, Sinha R, Kundu S (2021) Role of organosolv pretreatment on enzymatic hydrolysis of mustard biomass for increased saccharification. Biomass Convers Biorefin. https://doi.org/10. 1007/s13399-020-01251-6

30. Meng X, Bhagia S, Wang Y, Zhou Y, Pu Y, Dunlap JR, Shuai L, Ragauskas AJ, Yoo CG (2020) Effects of the advanced organosolv pretreatment strategies on structural properties of woody biomass. Ind Crops Prod 146:112144. https://doi.org/10.1016/j. indcrop.2020.112144

31. Zhang K, Pei Z, Wang D (2016) Organic solvent pretreatment of lignocellulosic biomass for biofuels and biochemicals: a review. Bioresour Technol 199:21-33. https://doi.org/10.1016/j.biortech. 2015.08.102

32. Wei W, Wu S, Xu S (2017) Enhancement of enzymatic saccharification of bagasse by ethanol-based organosolv auto-catalyzed pretreatment. J Chem Technol Biotechnol 92(3):580-587. https:// doi.org/10.1002/jctb.5036

33. Vedoya CI, Vallejos ME, Area MC, Felissia FE, Raffaeli N, da Silva Curvelo AA (2020) Hydrothermal treatment and organosolv pulping of softwood assisted by carbon dioxide. Ind Crops Prod 147:112244. https://doi.org/10.1016/j.indcrop.2020.112244

34. Cybulska I, Brudecki GP, Zembrzuska J, Schmidt JE, Lopez CG-B, Thomsen MH (2017) Organosolv delignification of agricultural residues (date palm fronds, Phoenix dactylifera $\mathrm{L}$.) of the United Arab Emirates. Appl Energy 185:1040-1050. https://doi. org/10.1016/j.apenergy.2016.01.094

35. Pan X, Xie D, Yu RW, Lam D, Saddler JN (2007) Pretreatment of lodgepole pine killed by mountain pine beetle using the ethanol organosolv process: fractionation and process optimization. Ind Eng Chem Res 46(8):2609-2617. https://doi.org/10.1021/ie061 5761

36. Santos TM, Rigual V, Oliet M, Alonso MV, Domínguez JC, Rodriguez F (2019) Two-step fractionation of Pinus radiata by autohydrolysis and organosolv delignification for enzymatic hydrolysis. J Chem Technol Biotechnol 94(12):3951-3959. https://doi.org/10. 1002/jctb.6197

37. Chen H, Zhao J, Hu T, Zhao X, Liu D (2015) A comparison of several organosolv pretreatments for improving the enzymatic hydrolysis of wheat straw: substrate digestibility, fermentability and structural features. Appl Energy 150:224-232. https://doi.org/ 10.1016/j.apenergy.2015.04.030

38. Asadi N, Zilouei H (2017) Optimization of organosolv pretreatment of rice straw for enhanced biohydrogen production using Enterobacter aerogenes. Bioresour Technol 227:335-344. https:// doi.org/10.1016/j.biortech.2016.12.073

39. Amiri H, Karimi K (2015) Improvement of acetone, butanol, and ethanol production from woody biomass using organosolv pretreatment. Bioproc Biosyst Eng 38(10):1959-1972. https://doi. org/10.1007/s00449-015-1437-0

40. Tongbuekeaw T, Sawangkeaw R, Chaiprapat S, Charnnok B (2021) Conversion of rubber wood waste to methane by ethanol organosolv pretreatment. Biomass Convers Biorefin 11(3):9991011. https://doi.org/10.1007/s13399-020-00710-4

41. Zheng A, Chen T, Sun J, Jiang L, Wu J, Zhao Z, Huang Z, Zhao K, Wei G, He F (2017) Toward fast pyrolysis-based biorefinery: selective production of platform chemicals from biomass by organosolv fractionation coupled with fast pyrolysis. ACS Sustainable Chem Eng 5(8):6507-6516. https://doi.org/10.1021/acssuschem eng.7b00622

42. García A, Labidi J, Belgacem MN, Bras J (2017) The nanocellulose biorefinery: woody versus herbaceous agricultural wastes for NCC production. Cellulose 24(2):693-704. https://doi.org/10. 1007/s10570-016-1144-2
43. Karnaouri A, Asimakopoulou G, Kalogiannis KG, Lappas AA, Topakas E (2021) Efficient production of nutraceuticals and lactic acid from lignocellulosic biomass by combining organosolv fractionation with enzymatic/fermentative routes. Bioresour Technol 341:125846. https://doi.org/10.1016/j.biortech.2021.125846

44. Sun FF, Zhao X, Hong J, Tang Y, Wang L, Sun H, Li X, Hu J (2016) Industrially relevant hydrolyzability and fermentability of sugarcane bagasse improved effectively by glycerol organosolv pretreatment. Biotechnol Biofuels 9(1):59. https://doi.org/10. 1186/s13068-016-0472-7

45. Tan X, Zhang Q, Wang W, Zhuang X, Deng Y, Yuan Z (2019) Comparison study of organosolv pretreatment on hybrid pennisetum for enzymatic saccharification and lignin isolation. Fuel 249:334-340. https://doi.org/10.1016/j.fuel.2019.03.117

46. Oroumei A, Fox B, Naebe M (2015) Thermal and rheological characteristics of biobased carbon fiber precursor derived from low molecular weight organosolv lignin. ACS Sustain Chem Eng 3(4):758-769. https://doi.org/10.1021/acssuschemeng.5b00097

47. García A, Spigno G, Labidi J (2017) Antioxidant and biocide behaviour of lignin fractions from apple tree pruning residues. Ind Crops Prod 104:242-252. https://doi.org/10.1016/j.indcrop. 2017.04.063

48. Kalami S, Chen N, Borazjani H, Nejad M (2018) Comparative analysis of different lignins as phenol replacement in phenolic adhesive formulations. Ind Crops Prod 125:520-528. https://doi. org/10.1016/j.indcrop.2018.09.037

49. Morales A, Labidi J, Gullón P (2021) Impact of the lignin type and source on the characteristics of physical lignin hydrogels. Sustain Mater Technol. https://doi.org/10.1016/j.susmat.2021.e00369

50. Lange J, Müller F, Takors R, Blombach B (2018) Harnessing novel chromosomal integration loci to utilize an organosolvderived hemicellulose fraction for isobutanol production with engineered Corynebacterium glutamicum. Microb Biotechnol 11(1):257-263. https://doi.org/10.1111/1751-7915.12879

51. Choi J-H, Jang S-K, Kim J-H, Park S-Y, Kim J-C, Jeong H, Kim H-Y, Choi I-G (2019) Simultaneous production of glucose, furfural, and ethanol organosolv lignin for total utilization of high recalcitrant biomass by organosolv pretreatment. Renew Energy 130:952-960. https://doi.org/10.1016/j.renene.2018.05.052

52. García-Torreiro M, Martínez-Patiño JC, Gullón B, Lú-Chau TA, Moreira MT, Lema JM, Eibes G (2018) Simultaneous valorization and detoxification of the hemicellulose rich liquor from the organosolv fractionation. Int Biodeterior Biodegrad 126:112-118. https://doi.org/10.1016/j.ibiod.2017.10.010

53. Pan X, Gilkes N, Kadla J, Pye K, Saka S, Gregg D, Ehara K, Xie D, Lam D, Saddler J (2006) Bioconversion of hybrid poplar to ethanol and co-products using an organosolv fractionation process: optimization of process yields. Biotechnol Bioeng 94(5):851-861. https://doi.org/10.1002/bit.20905

54. Goh CS, Tan HT, Lee KT, Brosse N (2011) Evaluation and optimization of organosolv pretreatment using combined severity factors and response surface methodology. Biomass bioenergy 35(9):4025-4033. https://doi.org/10.1016/j.biombioe.2011.06.034

55. Sluiter A, Hames B, Ruiz R, Scarlata C, Sluiter J, Templeton D, Crocker D (2008) Determination of structural carbohydrates and lignin in biomass. Laboratory analytical procedure. National Renewable Energy Laboratory, Golden, CO. NREL/ TP-510-42618.

56. Domínguez JC, Santos TM, Rigual V, Oliet M, Alonso MV, Rodriguez F (2018) Thermal stability, degradation kinetics, and molecular weight of organosolv lignins from Pinus radiata. Ind Crops Prod 111:889-898. https://doi.org/10.1016/j.indcrop.2017. 10.059

57. Ruiz HA, Silva DP, Ruzene DS, Lima LF, Vicente AA, Teixeira JA (2012) Bioethanol production from hydrothermal pretreated wheat straw by a flocculating Saccharomyces cerevisiae 
strain-effect of process conditions. Fuel 95:528-536. https://doi. org/10.1016/j.fuel.2011.10.060

58. Krogell J, Korotkova E, Eränen K, Pranovich A, Salmi T, Murzin D, Willför S (2013) Intensification of hemicellulose hot-water extraction from spruce wood in a batch extractor - effects of wood particle size. Bioresour Technol 143:212-220. https://doi.org/10. 1016/j.biortech.2013.05.110

59. Yang H, Yan R, Chen H, Lee DH, Zheng C (2007) Characteristics of hemicellulose, cellulose and lignin pyrolysis. Fuel 86(12):1781-1788. https://doi.org/10.1016/j.fuel.2006.12.013

60. Pandey K (1999) A study of chemical structure of soft and hardwood and wood polymers by FTIR spectroscopy. J Appl Polym Sci 71(12):1969-1975. https://doi.org/10.1002/(SICI)10974628(19990321)71:12/3C1969::AID-APP6/3E3.0.CO;2-D
61. Schwanninger M, Rodrigues JC, Pereira H, Hinterstoisser B (2004) Effects of short-time vibratory ball milling on the shape of FT-IR spectra of wood and cellulose. Vib Spectrosc 36(1):23-40. https://doi.org/10.1016/j.vibspec.2004.02.003

62. Carrillo F, Colom X, Sunol J, Saurina J (2004) Structural FTIR analysis and thermal characterisation of lyocell and viscose-type fibres. Eur Polym J 40(9):2229-2234. https://doi.org/10.1016/j. eurpolymj.2004.05.003

Publisher's note Springer Nature remains neutral with regard to jurisdictional claims in published maps and institutional affiliations. 